\title{
Qatar's Primary Health Care Medication Home Delivery Service: A Response Toward COVID-19
}

This article was published in the following Dove Press journal:

Journal of Multidisciplinary Healthcare

\author{
Manal Al-Zaidan' \\ Mohamed Izham Mohamed \\ Ibrahim (D) $)^{2}$ \\ Mohamed Ghaith Al-Kuwari $\mathbb{D B}^{3}$ \\ Azza Mustafa Mohammed (iD) \\ Mansoor Nawaz Mohammed ${ }^{4}$ \\ Samya Al Abdulla $\mathbb{D}^{5}$ \\ 'Pharmacy Department, Primary Health \\ Care Corporation, Doha, Qatar; \\ ${ }^{2}$ College of Pharmacy, QU Health, Qatar \\ University, Doha, Qatar; ${ }^{3}$ Directorate of \\ Strategy Planning and Health Intelligence, \\ Primary Health Care Corporation, Doha, \\ Qatar; ${ }^{4}$ Clinical Information Systems \\ Department, Primary Health Care \\ Corporation, Doha, Qatar; ${ }^{5}$ Directorate \\ of Operations, Primary Health Care \\ Corporation, Doha, Qatar
}

Correspondence: Manal Al-Zaidan Director of Pharmacy, P.O. Box 26555, Doha, Qatar

Tel + 974 4027II 03

Email malzaidan@phcc.gov.qa
Abstract: The COVID-19 pandemic has strained health care systems around the world. Pharmacists have made substantial contributions to the health care operations during the COVID-19 response. The Pharmacy Department at Qatar Primary Health Care Corporation (PHCC) acted proactively to ensure that all patients received their medications and their refilled prescriptions in time and without any disruption. The Medication Home Delivery Service was introduced and implemented for all Qatar residents to prevent unnecessary visits to health centers, minimize the spread of COVID-19 to vulnerable populations, especially those with multiple comorbidities, and protect health care workers from exposure to the virus. Moreover, several other precautionary measures were taken by the PHCC to ensure uninterrupted access to health care, including moving to a virtual health care delivery model. As of September 2020, the service had served around 64,213 patients since its launch in March 2020. In total, 70,357 medications were delivered and 69,092 (98.2\%) medication packages were delivered successfully to patients, with an average of 450.8 medication packages delivered per month. Despite various challenges, the PHCC is considering continuing the Medication Home Delivery Service in the long term to continue with a more effective and efficient service for patients during the coming months and years.

Keywords: COVID-19, pandemic, pharmacy service, medication home delivery, PHCC, Qatar

\section{Introduction}

On June 30th 2020, the WHO marked 6 months since it started receiving initial reports about pneumonia clusters in the city of Wuhan, China. ${ }^{1}$ That was the start of the coronavirus disease 2019 (COVID-19) pandemic that, so far, has affected around 15 million people around the globe and caused more than 500,000 deaths. ${ }^{1}$ COVID-19 is caused by the novel coronavirus severe acute respiratory syndrome coronavirus-2 (SARS-CoV-2). ${ }^{2}$ The virus can be transmitted very rapidly through close person-toperson contact, mainly through respiratory droplets. ${ }^{3}$ COVID-19 can cause a wide spectrum of respiratory problems. It can cause mild infection with symptoms such as fever, cough, and shortness of breath. ${ }^{4}$ However, it can also present in a very severe form, causing pneumonia, severe acute respiratory syndrome, with organ failure and sometimes death. ${ }^{4}$

In Qatar, as of January 13th 2021, a total of 146,279 individuals have been infected with COVID-19 since the start of the epidemic, with 142,938 patients having recovered and a death toll of 246 people. ${ }^{5}$ The State of Qatar has taken multiple precautionary measures to control the spread of COVID-19 and protect vulnerable populations, such as implementing social distancing policies, including 
working remotely. ${ }^{6}$ In addition, the country mandated all residents to install and use a contact tracing app named Ehteraz $^{\circledR .6}$ In the health sector, Qatar's Ministry of Public Health implemented several remote channels to access health care services. The Primary Health Care Corporation (PHCC), which is the main provider of primary care in Qatar, has moved to a virtual care model with "remote telephone and video consultations for patients requiring both routine and priority care". 7

During epidemics, physical distancing becomes of the highest importance. As a result, it is essential that patients are able to communicate virtually with the pharmacists to refill their prescriptions or ask questions about medication management. ${ }^{8}$ The service has been implemented successfully in China during COVID-19, with patients being offered online drug consultation, education, medication prescription, and home delivery. ${ }^{4}$ Another initiative of a mail order pharmacy service has been established in Cape Town, South Africa, in response to COVID-19, with more than 3000 parcels being delivered to patients per day. ${ }^{9}$

Existing research demonstrates that virtual pharmacy services with home delivery provide an efficient, costeffective way to enhance patients' care. ${ }^{8}$ Furthermore, the service is helpful in improving adherence rates to medication. ${ }^{8}$ Schmittdiel et al reported that mail order pharmacy services improved patients' access to medication, especially for those with disabilities. Moreover, it correlated with "greater adherence to diabetes and antihypertensive medications", which led to a reduction in the preventable utilization of emergency departments over time. ${ }^{10}$

In March 2020, the PHCC launched a service for the home delivery of prescribed medications in response to COVID-19 to prevent unnecessary visits to health centers, minimize patients' and health care workers' exposure, and reduce the risk of community spread of the disease. The service was established in collaboration with the Ministry of Public Health, which facilitated the implementation and provision of the service free of charge to the residents of Qatar. All medications were delivered via Qatar Post (Q-Post) (https:// qatarpost.qa/home), the governmental agency that provides national postal services.

\section{Objectives}

This paper aims to:

1. Describe the development and implementation of PHCC's Medication Home Delivery Service
2. Examine the service's process metrics, including:

i. the total number of patients who received their delivered medications per phase of implementation

ii. the total number and percentage of medications successfully delivered to patients' homes per geographical region

iii. the average number of medications delivered per day per phase of implementation

iv. the percentage of undelivered medication packages which had to be returned to the pharmacy

3. Describe the challenges and opportunities for improvement.

\section{Program Description}

Many of the routine pharmacy dispensing activities do not require direct patient contact. The PHCC implemented the home delivery of prescribed medications to minimize the risk of exposure for pharmacy staff and the general population, especially vulnerable people with multiple comorbidities who are at increased risk for COVID-19. The service includes medication refills, teleconsultation, virtual consultation, and home healthcare. The service does not include narcotic drugs, psychotropic medications, or emergency and urgent prescriptions.

\section{Service Workflow}

The service consisted of the following steps, as illustrated in Figure 1.

\section{Implementation Phases}

1. Service design phase. This phase consisted of the following steps:

i. Developing standard operating procedures (SOP) for the new service that can be updated with time based on challenges arising during full implementation of the service

ii. Developing pharmacy auxiliary labels added on to the dispensed medication packages to provide supplementary information for the drivers to best handle the medications

iii. Receiving Q-Post bags and barcodes

iv. Developing refill reports in the CERNER ${ }^{\circledR}$ (electronic health record) electronic system to be accessed by pharmacists 


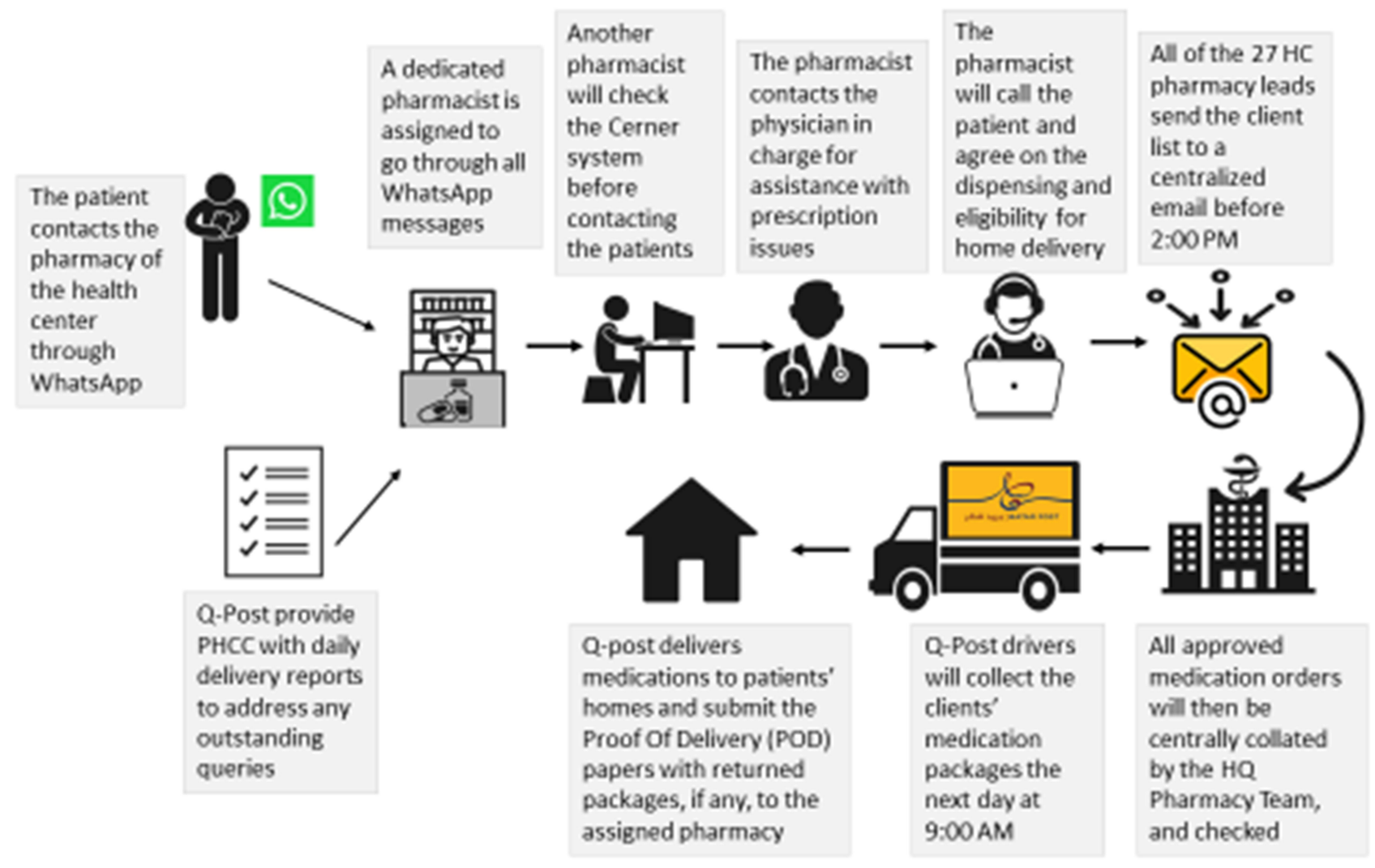

Figure I Service workflow.

v. Training of all 60 Q-Post assigned drivers by Q-Post's head of sales and marketing and PHCC's director of pharmacy

vi. Training of all pharmacy leads

vii. Developing the WhatsApp workflow and finalizing it with feedback from all 27 pharmacy leads

viii. Developing virtual consultation prescription reports and training pharmacists to access them through CERNER ${ }^{\circledR}$.

2. Phase 1. This phase started on March 24th, and consisted of the following steps:

i. Rolling out the service, starting with Qatari and patients who are exempted from the medication payment scheme

ii. Identifying collection points for Q-Post at 21 health centers, which will cover all of the PHCC's 27 health centers

iii. Pharmacists starting to contact patients, offer them the service, and introduce the WhatsApp communication tools. In this phase, pending medication refills were prioritized.
3. Phase 2. This phase started on April 6th, and consisted of the following steps:

i. Expanding the service to cover non-Qatari PHCC clients, starting with only nine health centers, and starting with three health centers in the first week

ii. Payment being taken through bank cards using point-of-sale devices at the patients' home location

iii. Q-Post collection points continuing to be located at 21 health centers, yet covering all of the PHCC's 27 health centers.

4. Phase 3. This phase included scaling up of the service to cover all PHCC clients, Qatari and expats, at all of the PHCC's health centers.

5. Developing the Medication Home Delivery SharePoint Tool to automate and standardize the operations of the service. The tool was piloted successfully in one health center on July 5th 2020 . The tool included an online payment option, which was piloted in the same health center on August 12th 2020. The rollout for the complete implementation was achieved on August 25th 2020. 


\section{Service Promotion}

Multiple media platforms such as television, radio channels, and daily newspapers were used to inform the community. In addition, constant messages were shared via WhatsApp and social media through Twitter and Facebook.

\section{Service Process Outcomes}

To be able to carry out an initial evaluation of the medication home delivery, we assessed the process outcomes of the service. Between March 24th and September 30th 2020 , a total of 64,213 patients received their medications through home delivery (Figure 2), and 69,092 out of $70,357(98.2 \%)$ medication packages were delivered successfully (Table 1). During the first phase of implementation, an average of 450.8 packages was delivered per day. The average number of deliveries increased to 433 and 548 per day in Phases 2 and 3, respectively, which represents a percentage increase of $78 \%$ between Phase 1 and Phase 3.

The percentage of returned packages (during the period from March to July 2020) ranged from $2.37 \%$ in the Central Region and $2.10 \%$ in the Northern Region to $0.90 \%$ in the Western Region, which is well below the $5 \%$ quality control benchmark identified at the beginning of the service (Table 2). Common reasons for returned packages were "no one answered or opened the door", "the client refused to accept the parcel", "the address was incorrect", "incorrect mobile number", "the client did not pick up the phone", and "he was not at home at time of delivery".
Out of the total number of patients $(n=36,697$; no duplication) who received home delivery medications between March and June 2020, around 12,409 were Qatari [male 4169 (34\%); female 8240 (66\%)] and 24,288 were the non-Qatari male 10,680 (44\%); female $13,608(56 \%)]$. Further analysis indicated that approximately $79 \%$ of them $(n=28,813)$ had chronic diseases, while approximately $8 \% \quad(n=5421)$ were pregnant. Table 3 shows the top medical conditions, top 10 medication items for home delivery service, and number of patients who received the medications. The top 3 health problems for which medications were dispensed for home delivery service were diabetes mellitus (32.7\%), hypertension $(20.8 \%)$, and vitamin D deficiency $(13.0 \%)$. Out of the total patients with chronic diseases $(n=69,508$ from March to August 2020), 22,729 had diabetes mellitus ( $n=4911$ type 1 and $n=17,818$ type 2 ).

\section{Challenges and Opportunities for Improvement}

Pharmacy is an integral part of successful population health initiatives, and pharmacists have made substantial contributions to health care operations during the COVID19 response. $^{4}$

The most important benefit of implementing the prescribed medication home services is reducing the spread of COVID-19 among vulnerable populations and health care workers. In addition, using the service in the long run has the potential to avoid lost productivity due to people taking time away from work to collect medications. ${ }^{9}$ The service has the potential to improve patients' compliance

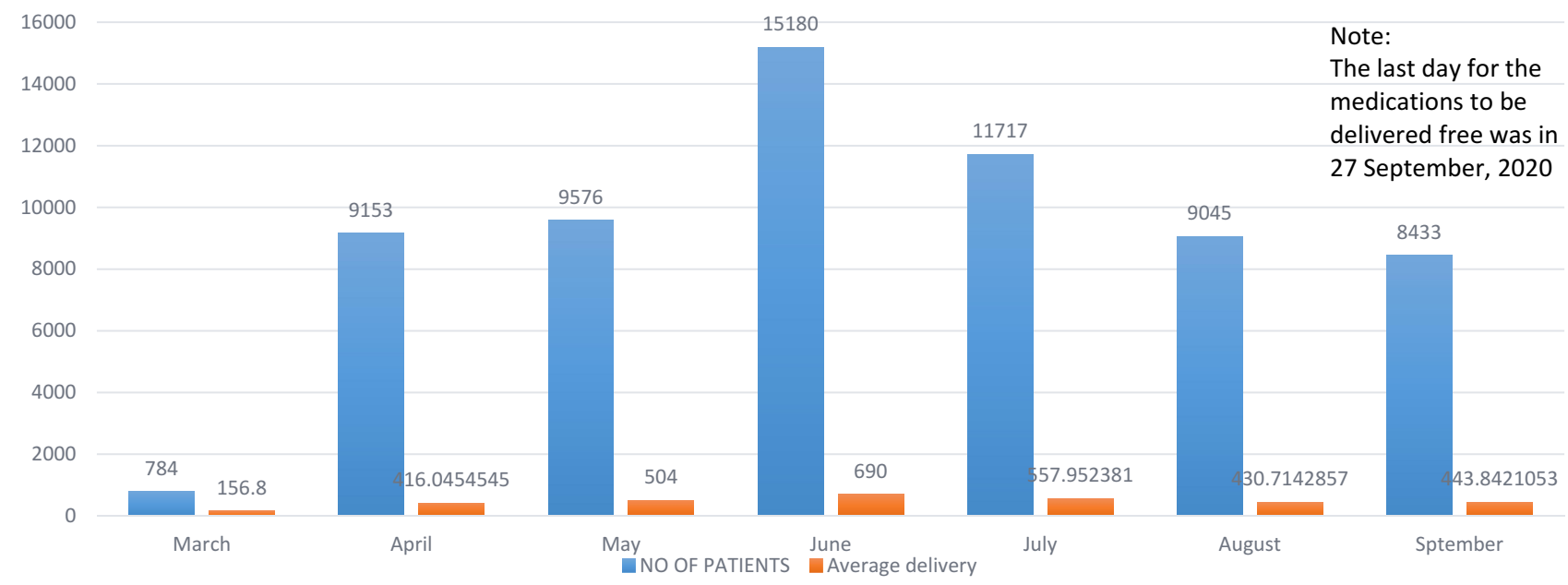

The total number of patients that received their delivered medications

Figure 2 The total number of patients that received their delivered medications. 
Table I Total Number and Percentage of Medications Successfully Delivered to Patients' Homes (March to September 2020)

\begin{tabular}{|l|c|c|c|c|c|}
\hline Month & $\begin{array}{c}\text { Number of } \\
\text { Patients }\end{array}$ & $\begin{array}{c}\text { Average } \\
\text { Delivery }\end{array}$ & $\begin{array}{c}\text { Number of } \\
\text { Items }\end{array}$ & $\begin{array}{c}\text { Number of Items } \\
\text { Delivered }\end{array}$ & $\begin{array}{c}\text { Number of Items } \\
\text { Returned }\end{array}$ \\
\hline March & 784 & 156.8 & 990 & 958 & 32 \\
April & 9153 & 416.0 & 11,092 & 10,880 & 212 \\
May & 9576 & 504.0 & 10,345 & 10,095 & 250 \\
June & 15,180 & 690.0 & 16,361 & 16,120 & 241 \\
July & 11,717 & 558.0 & 12,554 & 12,345 & 209 \\
August & 9045 & 430.7 & 9640 & 9476 & 164 \\
September & 8758 & 398.1 & 9375 & 9218 & 157 \\
\hline
\end{tabular}

Table 2 Total Number and Percentage of Medications Successfully Delivered to Patients' Homes per Geographical Region (March to July 2020)

\begin{tabular}{|l|c|c|c|c|c|c|}
\hline $\begin{array}{l}\text { Geographical } \\
\text { Region }\end{array}$ & $\begin{array}{c}\text { Number of } \\
\text { Patients }\end{array}$ & $\begin{array}{c}\text { Number of } \\
\text { Packages }\end{array}$ & $\begin{array}{c}\text { Successfully Delivered } \\
\text { Packages }\end{array}$ & $\%$ & $\begin{array}{c}\text { Returned } \\
\text { Packages }\end{array}$ & $\begin{array}{c}\% \\
\text { Northern Region }\end{array}$ \\
Central Region & 15,979 & 17,660 & 17,289 & 978.90 & 371 & 2.10 \\
Western Region & 14,479 & 16,831 & 18,385 & 97.63 & 446 & 2.37 \\
Total & 47,526 & 52,531 & 51,596 & 99.10 & 145 & 0.90 \\
\hline
\end{tabular}

Table 3 Top Medical Conditions and Number of Medications Dispensed for Home Delivery Patients

\begin{tabular}{|l|l|l|}
\hline Medical Condition & Number of Patients* & Percentage \\
\hline Diabetes mellitus & 22,729 & 32.7 \\
Hypertension & 14,479 & 20.8 \\
Vitamin D deficiency & 9061 & 13.0 \\
Dyslipidemia & 7621 & 11.0 \\
Pregnant & 5421 & 7.8 \\
Hypothyroidism & 4255 & 6.2 \\
Viral upper respiratory tract infection & 3423 & 4.9 \\
Severe acute respiratory syndrome coronavirus & 2519 & 3.6 \\
\hline Medications Dispensed & & \\
Ergocalciferol & 39,783 & 22.4 \\
Metformin & 20,233 & 11.4 \\
Rosuvastatin & 17,582 & 9.9 \\
Atorvastatin & 17,443 & 9.8 \\
Levothyroxine & 16,434 & 9.3 \\
Paracetamol & 16,089 & 9.1 \\
Ocular lubricant & 13,665 & 7.7 \\
Sitagliptin/metformin & 13,565 & 7.7 \\
Aspirin & 12,537 & 7.1 \\
Amlodipine & 9940 & 5.6 \\
\hline Noter & & \\
\hline
\end{tabular}

Note: *Number of unique patients (ie, without duplication).

with their medications and it enhances their communication with pharmacists and pharmacy staff.

One of the challenges of the home delivery service is that it will require effective communication, support, and coordination between pharmacy, primary care, Q-Post, and other community-based services if the service is expanded on a larger level. ${ }^{9}$ Another challenge is the return rate of undelivered packages. Each delivery costs around QAR30, and undelivered packages can increase the overall cost of the service, not to mention the inconvenience caused to 
patients. Another potential challenge could be medications not reaching patients on time, or patients receiving incomplete medications owing to miscommunication between the patient and the pharmacist. Pharmacists, along with other pharmacy staff, should receive constant training on effective communication with patients using virtual services to avoid these challenges.

The Medication Home Delivery Service is expected to continue in the long term and become a major service in the State of Qatar. Some of the suggested future plans to advance the service include:

(i) Centralizing the service

(ii) Completing the implementation of the tracking and communication of deliveries tool

(iii) Completing the implementation of the online payment option

(iv) Developing an app that works specifically for this service

(v) Training pharmacists in effective communication strategies with the public

(vi) Conducting surveys and collecting qualitative data to understand the community's perceptions and opinions about the service.

\section{Conclusion}

The COVID-19 pandemic has strained health systems across the world. Qatar's health sector has been able to respond quickly and efficiently to manage the outbreak. Health care workers across the country have been trained to reinforce infection prevention and control, implement case management, and move toward a virtual care model. The PHCC's Medication Home Delivery Service is a major service for the public during the pandemic and in the future. It reduces overcrowding and unnecessary visits to health centers. Moreover, it allows the patients to receive their medications without interruption during this critical time. More research is needed to explore patients' opinions about and satisfaction with the service, and whether it might be beneficial for them to continue using the service after the pandemic. This service could be used in normal situations to avoid unnecessary visits and to make care more accessible for elderly patients and those with non-communicable diseases.

\section{Data Sharing Statement}

No additional data are available.

\section{Acknowledgments}

The publication open access fee is paid by Clinical Research Department, Clinical Affairs Directorate of PHCC (Approval no: PHCC/DCR/2020/09/112). We really appreciate the contributions of the following individuals in ensuring the success of the service: HICT: Alexandra Terazi, Mustafa Hussein Sharara, Veeraiah Choudary Chalasani, Khaleel Hussain Syed, Seetharam Gandhy, Mahaboob Sameer Shaik, Kiran Rathish; Pharmacy: PHCC pharmacy staff, pharmacy leads, Wael Ezzeldin Saeed, Dr. Jamal Kasasbeh, Anjum Habib Sair; Finance: Sherif Fadda, Hassan Raza Syed, PHCC billing officers; Procurement and contracts: Sherif Sobeih; Operations: Regional Directors, Assistant Regional Directors, Health Center Managers; and MOPH: Dr. Juliet Ibrahim.

\section{Author Contributions}

All authors made a significant contribution to the work reported, whether that is in the conception, study design, execution, acquisition of data, analysis and interpretation, or in all these areas; took part in drafting, revising or critically reviewing the article; gave final approval of the version to be published; have agreed on the journal to which the article has been submitted; and agree to be accountable for all aspects of the work.

\section{Funding}

The authors did not use specific funding for this research from any funding agency in the public, commercial, or not-for-profit sectors.

\section{Disclosure}

The authors report no conflicts of interest in this work.

\section{References}

1. World Health Organization (WHO). WHO Director-General's Opening Remarks at the Media Briefing on COVID-19. Geneva; 2020. Available from: https://www.who.int/dg/speeches/detail/who-directorgeneral-s-opening-remarks-at-the-media-briefing-on-covid-19-29june-2020. Accessed February 10, 2021.

2. Centers for Disease Control and Prevention (CDC). Symptoms of coronavirus. 2020. Available from: https://www.cdc.gov/coronavirus/ 2019-ncov/symptoms-testing/symptoms.html. Accessed February 10, 2021.

3. Centers for Disease Control and Prevention (CDC). Frequently asked questions. 2020. Available from: https://www.cdc.gov/coronavirus/ 2019-ncov/faq.html\#Spread. Accessed February 10, 2021.

4. Liu S, Luo P, Tang M, et al. Providing pharmacy services during the coronavirus pandemic. Int J Clin Pharm. 2020;42(2):299-304. doi:10.1007/s11096-020-01017-0 
5. Ministry of Public Health-Qatar. COVID-19. 2020. Available from: https://covid19.moph.gov.qa/EN/Pages/default.aspx. Accessed Febr uary $10,2021$.

6. Government Communication Office-Qatar. Preventative measures. 2020. Available from: https://www.gco.gov.qa/en/preventative-mea sures/. Accessed February 10, 2021.

7. Ministry of Public Health-Qatar. Qatar launching new remote healthcare services. 2020. Available from: https://www.moph.gov.qa/eng lish/mediacenter/News/Pages/NewsDetails.aspx?ItemId=115.

Accessed February 10, 2021.
8. Elbeddini A, Yeats A. intervention amid the coronavirus disease 2019 (COVID-19) pandemic: from direct patient care to telemedicine. $J$ Pharm Policy Pract. 2020;13(23). doi:10.1186/s40545-020-00229-z

9. Brey Z, Mash R, Goliath C, Roman D. Home delivery of medication during coronavirus disease 2019, Cape Town, South Africa: short report. Afr J Prim Health Care Fam Med. 2020;12(1):e1-e4. doi:10.4102/phcfm.v12i1.2449

10. Schmittdiel JA, Karter AJ, Dyer WT, Chan J, Duru OK. Safety and effectiveness of mail order pharmacy use in diabetes. Am J Manag Care. 2013;19(11):882-887.

\section{Publish your work in this journal}

The Journal of Multidisciplinary Healthcare is an international, peerreviewed open-access journal that aims to represent and publish research in healthcare areas delivered by practitioners of different disciplines. This includes studies and reviews conducted by multidisciplinary teams as well as research which evaluates the results or conduct of such teams or healthcare processes in general. The journal covers a very wide range of areas and welcomes submissions from practitioners at all levels, from all over the world. The manuscript management system is completely online and includes a very quick and fair peer-review system. Visit http://www.dovepress.com/testimonials. php to read real quotes from published authors. 